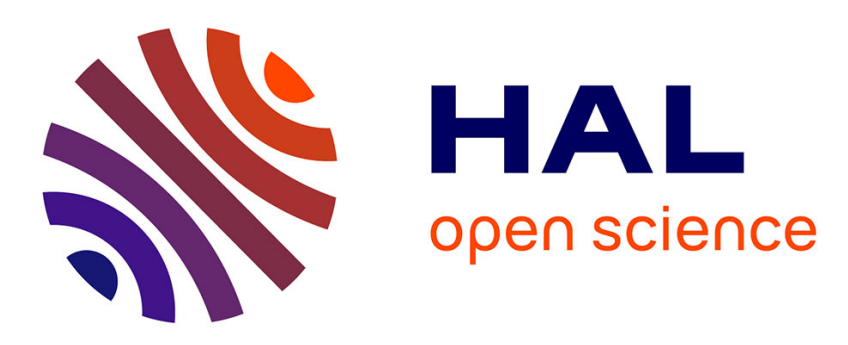

\title{
Cross-validation of Advanced Microwave Sounding Unit and lidar for long-term upper-stratospheric temperature monitoring
}

Beatriz M. Funatsu, Chantal Claud, Philippe Keckhut, Alain Hauchecorne

\section{- To cite this version:}

Beatriz M. Funatsu, Chantal Claud, Philippe Keckhut, Alain Hauchecorne. Cross-validation of Advanced Microwave Sounding Unit and lidar for long-term upper-stratospheric temperature monitoring. Journal of Geophysical Research: Atmospheres, 2008, 113 (D23), pp.D23108. 10.1029/2008JD010743 . hal-00346311

\section{HAL Id: hal-00346311 \\ https://hal.science/hal-00346311}

Submitted on 5 Feb 2016

HAL is a multi-disciplinary open access archive for the deposit and dissemination of scientific research documents, whether they are published or not. The documents may come from teaching and research institutions in France or abroad, or from public or private research centers.
L'archive ouverte pluridisciplinaire HAL, est destinée au dépôt et à la diffusion de documents scientifiques de niveau recherche, publiés ou non, émanant des établissements d'enseignement et de recherche français ou étrangers, des laboratoires publics ou privés. 


\title{
Cross-validation of Advanced Microwave Sounding Unit and lidar for long-term upper-stratospheric temperature monitoring
}

\author{
Beatriz M. Funatsu, ${ }^{1}$ Chantal Claud, ${ }^{1}$ Philippe Keckhut, ${ }^{2}$ and Alain Hauchecorne ${ }^{2}$ \\ Received 8 July 2008; revised 16 September 2008; accepted 30 September 2008; published 11 December 2008.
}

[1] A comparison between NOAA-16 Advanced Microwave Sounding Unit (AMSU) and lidar upper-stratospheric temperature measurements for the period from 2001 to 2007 for purposes of temperature monitoring is presented. Monthly means of lidar data from the Observatoire de Haute-Provence and AMSU data over Western Europe were found to have high correlation, particularly in winter months, when based on measurements for overlapping nights but lower correlation when different sets of days were used for the monthly mean calculation. This result implies that temperatures from lidar measurements are representative of an area relatively larger than its location, in a monthly mean timescale. However, the effect of temporal sampling arising from the fact that lidar measurements are only made in nights without visible cloud cover introduces discrepancies that propagate on the calculation of temperature tendencies. The estimated cooling rate based on lidar and AMSU data sets are in good agreement, although they are more negative than trends previously found based on the Stratospheric Sounding Unit data record from 1979 to 2005 for the middle-upper stratosphere. In addition, the effect of NOAA satellite drift was to produce a difference (between monthly means for day and night passes) of up to $3 \mathrm{~K}$ near the stratopause, which must be accounted for particularly when a longer time series will be available.

Citation: Funatsu, B. M., C. Claud, P. Keckhut, and A. Hauchecorne (2008), Cross-validation of Advanced Microwave Sounding Unit and lidar for long-term upper-stratospheric temperature monitoring, J. Geophys. Res., 113, D23108, doi:10.1029/2008JD010743.

\section{Introduction}

[2] The stratosphere has cooled significantly over the period 1979-2000 [e.g., Ramaswamy et al., 2001]. While sea surface temperature is the main driver for dynamical changes, stratospheric ozone depletion, increase of wellmixed greenhouse gases and water vapor are direct radiative forcings leading to this observed cooling of the middle atmosphere [e.g., Shine et al., 2003; Lahoz, 2000; Manzini et al., 2003; Hare et al., 2004; Forster and Shine, 1997; Langematz et al., 2003; Cagnazzo et al., 2006]. At the present time, it is still unclear whether the stratosphere will continue to cool with a similar rate [e.g., Eyring et al., 2007] because of opposing effects of the present reduction of anthropogenic halogen loading (which should lead to an ozone recovery) and the continuous increase in atmospheric greenhouse gases concentrations. The stratospheric composition and dynamics impact the climate by regulating the magnitude and distribution of important climate forcing agents, such as water vapor and ozone [e.g., IPCC, 2001; Song and Robinson, 2004; Scaife et al., 2005; Overland et

\footnotetext{
${ }^{1}$ Laboratoire de Météorologie Dynamique/IPSL, CNRS, Palaiseau, France.

${ }^{2}$ Service d'Aéronomie/IPSL, Université Versailles St-Quentin, CNRS, Verrières-le Buisson, France.

Copyright 2008 by the American Geophysical Union. 0148-0227/08/2008JD010743
}

al., 2008; Sigmond et al., 2008]. Stratospheric temperature, in turn, is a fingerprint of climate and a good proxy of both stratospheric composition and dynamic changes as well as of climate changes. A precise monitoring of the stratospheric temperature on a global scale is therefore essential and should take advantage of space and ground instruments.

[3] The longest stratospheric temperature data are from radiosondes extending back to the late 1950s and for which they has been several changes in instrumentation [e.g., Free and Seidel, 2005]. They however seldom go above $20 \mathrm{hPa}$. The only global long-term source of temperature of the middle atmosphere is provided by satellites. The main source of satellite-based upper air temperature records for the period 1979-2004 was the Stratospheric Sounding Unit (SSU) and to some extent the Microwave Sounding Unit (MSU), onboard NOAA-operational weather satellites. SSU is a step-scanned infrared spectrometer which provided information from about 15 to $60 \mathrm{~km}$ through three $\mathrm{CO}_{2}$ channels, while MSU is a microwave radiometer with 4 channels sensitive to frequencies in the 50 to $60 \mathrm{GHz}$ oxygen absorption complex, with weighting functions covering up to the lower stratosphere. It appears that SSU measurements are sensitive to changing weighting functions because of $\mathrm{CO}_{2}$ increase [Shine et al., 2008]. Surface-based lidars are another source of temperature measurements throughout the stratosphere covering altitudes in the range $30-80 \mathrm{~km}$ [Keckhut et al., 2004] that were deployed within the Network for the Detection of Stratospheric Change 


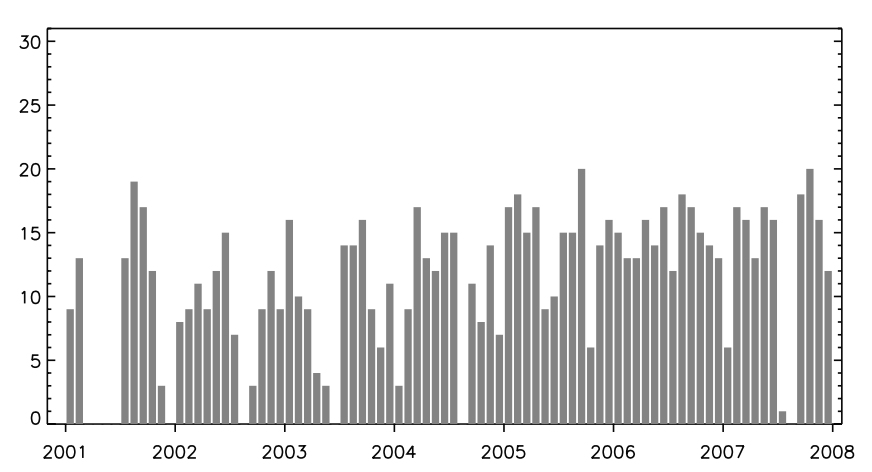

Figure 1. Total monthly number of days with lidar measurements, between 2001 and 2007.

[Kurylo and Solomon, 1990], and are currently part of the Network for the Detection of Atmospheric Composition Change (NDACC). Several locations from poles to the equator are available and will continue in the future. Among them, the Observatory of Haute-Provence (OHP) has allowed deriving local trends [Keckhut et al., 1995] from temperature series obtained since 1979.

[4] The last assessment of stratospheric temperature trends [Randel et al., 2008] stressed the need for an improved understanding of the reliability of the data used for assessing the trends. For example, SSU and lidar have shown discrepancies that are not very well understood. Effects of the temporal sampling (arising from the fact that lidar observations are only obtained during clear sky nights, i.e., without visible clouds), and the spatial sampling (resulting from the fact that this is a local measurement) have never been explicitly addressed, and may be a source of discrepancy compared to continuous measurements provided for example, by satellites. SSU series have been stopped and since 1998 expanded by the Advanced Microwave Sounding Unit (AMSU), which has improved spatial and spectral resolution (6 stratospheric channels) and extending altitude range up to the stratopause. The AMSU instrument has hence been chosen as a sentinel for the next 2 decades on successive NOAA, Metop/ESA-EUMETSAT and EOS/NASA platforms, and provides twice-daily (ascending and descending passes) global coverage, independent of cloud cover for channels sampling at or above the tropopause. Although AMSU data near the tropopause (channel 9) have been used to complement time series of previous MSU channel 4 data [e.g., Randel et al., 2008], to the authors' knowledge, AMSU data in the upper stratosphere $(30-50 \mathrm{~km})$ have not yet been explored in detail for the purpose of stratospheric temperature monitoring. This study is part of the international effort of temperature assessment for stratospheric monitoring and aims at (1) cross-validating lidar temperatures and AMSU brightness temperatures, and (2) better characterizing the impact of the temporal and spatial sampling on the calculation of trends. In particular, we use lidar data from OHP, which has been critically reviewed [Keckhut et al., 1993] and previously used for cross-validation purposes [e.g., Singh et al., 1996; Fishbein et al., 1996; Remsberg et al., 2002].

[5] The article is organized as follows. In section 2 we present the data used in this study. Section 3 presents a comparison between lidar and AMSU data, addressing the temporal and spatial sampling issues. The effect of diurnal tides is discussed in section 4 , and section 5 presents final remarks and conclusions.

\section{Data}

\subsection{OHP Lidar}

[6] Routine Rayleigh Lidar measurements are conducted since 1979 at Observatory of Haute-Provence in southern France $\left(44^{\circ} \mathrm{N} 6^{\circ} \mathrm{E}\right)$. Temperature profiles are derived from molecular scattering caused by the emission of a shortduration laser pulse in the zenith direction [Hauchecorne and Chanin, 1980]. In the upper part of the profile, the errors are larger and are mainly due to uncertainties on the reference pressure needed to initialize the data inversion and photon noise [Keckhut et al., 1993]. With powerful lidar (large collector and powerful laser), initialization effects are kept back to the upper mesosphere and the statistical noise is better than $1 \mathrm{~K}$ below $70 \mathrm{~km}$ and is even better at lower altitude up to a few tenths of degree at $30 \mathrm{~km}$. The typical integration time is of 2 to 4 hours. Other sources of uncertainty and bias in lidar-derived temperatures may arise in the lower part of the profile $(30-35 \mathrm{~km})$ because of the presence of aerosols, nonlinearity of the detector, and misalignment effects. However, measurement noise is increased by solar irradiance and for cloudy conditions; therefore operations are restricted to clear nights. Some breaks in the temporal continuity of the lidar series may occur by changes of some components. This is an expected outcome for any instruments operating over decades. As part of the Network for the Detection of Atmospheric Composition Change (NDACC), regular inter-comparisons using mobile instruments have been performed [Singh et al., 1996; Keckhut et al., 2004] as well as many inter-calibration campaigns with satellite sensors. Here we use data from 2001 to 2007, and Figure 1 shows the number of days for each month in this period for which a lidar measurement is available. There are typically between 10 and 15 measurements in a given month, for all months regardless of season (except for the extended period between March and June 2001 when data was not available due to local instrument adjustments).

\subsection{AMSU Temperature Series}

[7] AMSU is a cross-scanning microwave instrument which consists of two modules: AMSU-A, and AMSU-B. The latter has two atmospheric window channels and three channels along the wings of the water vapor absorption band centered at $183 \mathrm{GHz}$ providing data on the atmospheric humidity, and is not used in the present study. AMSU-A

Table 1. Frequencies and Band Width of AMSU-A Mid- and Upper-Stratospheric Channels

\begin{tabular}{cccc}
\hline $\begin{array}{c}\text { Channel } \\
\text { Number }\end{array}$ & $\begin{array}{c}\text { Center } \\
\text { Frequency }(\mathrm{GHz})\end{array}$ & $\begin{array}{c}\text { Band } \\
\text { Width }(\mathrm{MHz})\end{array}$ & $\begin{array}{c}\text { Measured } \\
\text { Noise }(\mathrm{K})^{\mathrm{a}}\end{array}$ \\
\hline 9 & $57.29(\mathrm{fo})$ & 310 & 0.24 \\
10 & fo \pm 0.217 & 76 & 0.25 \\
11 & fo $\pm 0.322 \pm 0.048$ & 34 & 0.28 \\
12 & fo $\pm 0.322 \pm 0.022$ & 15 & 0.40 \\
13 & fo $\pm 0.322 \pm 0.010$ & 8 & 0.54 \\
14 & fo $\pm 0.322 \pm 0.004$ & 3 & 0.91 \\
\hline
\end{tabular}

${ }^{\mathrm{a}}$ From Goldberg et al. [2001]. 
Table 2. Mean Absolute Difference (K) Between Annual Cycle of Operational, AMSU, and Lidar Temperatures ${ }^{\mathrm{a}}$

\begin{tabular}{|c|c|c|c|c|c|c|c|c|c|}
\hline$\underline{\text { Lidar }}$ & AMSU & & & $\underline{\text { Lidar }}$ & AMSU & OPERA & $\underline{\text { Lidar }}$ & AMSU & OPERA \\
\hline$(\mathrm{km})$ & ch 12 & $10 \mathrm{hPa}$ & $7 \mathrm{hPa}$ & $(\mathrm{km})$ & ch 13 & $5 \mathrm{hPa}$ & $(\mathrm{km})$ & ch 14 & $3 \mathrm{hPa}$ \\
\hline 30 & 5.31 & 2.06 & 6.57 & 34 & 7.16 & 3.32 & 38 & 6.49 & 4.57 \\
\hline 31 & 2.98 & 1.99 & 4.24 & 35 & 4.51 & 2.79 & 39 & 3.81 & 3.94 \\
\hline 32 & 1.31 & 3.23 & 2.48 & 36 & 2.68 & 3.23 & 40 & 2.72 & 4.35 \\
\hline 33 & 1.78 & 5.47 & 2.42 & 37 & 2.53 & 5.33 & 41 & 2.89 & 5.47 \\
\hline 34 & 4.06 & 7.94 & 3.04 & 38 & 4.30 & 8.32 & 42 & 5.30 & 7.92 \\
\hline
\end{tabular}

${ }^{\mathrm{a}}$ Bolded values are the smallest absolute difference between lidar and either AMSU or operational data.

has 12 channels between 50 and $58 \mathrm{GHz}$ in the Oxygen band, allowing the observation of the temperature structure of the atmosphere from the surface until $\sim 50 \mathrm{~km}$. More specifically, 6 channels (from 9 to 14) sound the stratosphere (Table 1). The swath width is of approximately $2300 \mathrm{~km}$ and AMSU-A spatial resolution ranges from $48 \mathrm{~km}$ at nadir to about $150 \mathrm{~km}$ at the edges. AMSU instrument has been collecting observations onboard NOAA-15, -16, -17 and -18 polar-orbiting satellites starting in 1998, 2000, 2002, and 2005 respectively. In the present study we use NOAA-16 AMSU-A for the period of January 2001 to December 2007, as it consists of a homogenous data set and avoids inter-satellite biases. Unless otherwise stated, only night (descending) passes of AMSU are considered, as lidar measurements are done at night-time. AMSU data suffers from the limb effect, which affects the temperature measurements mostly at the tracking outer wings [Goldberg et al., 2001]. To avoid the use of correction coefficients which may introduce additional errors, in the present study we use only the brightness temperature of near-nadir measurements. AMSU data is averaged over the area $\left[40^{\circ}-45^{\circ} \mathrm{N}, 10^{\circ} \mathrm{W}-\right.$ $\left.20^{\circ} \mathrm{E}\right]$ for comparison with OHP lidar measurements.

\subsection{ECMWF Operational Data Set}

[8] Since NOAA-16 data is available only from late 2000, the overlap with the European Centre for Mediumrange Weather Forecasts (ECMWF) Re-analysis (ERA-40) data set which ends in August 2002 is too short to yield a meaningful comparison. We use instead temperature data from the ECMWF Operational data set (hereafter referred simply as operational data), from 2002 onward, with a $1.125^{\circ}$ latitude $\times 1.125^{\circ}$ longitude resolution and at vertical levels ranging from 20 to $1 \mathrm{hPa}$. Vertical resolution is nearly uniform and of about $1.5 \mathrm{~km}$ in this region [Simmons et al., 2005]. The operational system assimilates AMSU-A data (among other satellite and radiosonde data), and they were found to have the most direct influence on the middle atmospheric analysis [Simmons et al., 2005]. However it is not clear what are the relative contributions of the assimilation of AMSU and the physics of the model on the stratospheric temperature output. The temperature data was averaged over the four gridpoints nearest to OHP location $\left(43.875^{\circ}-45^{\circ} \mathrm{N}, 3.375^{\circ}-4.5^{\circ} \mathrm{E}\right)$, and like AMSU data, only data at 00 UTC were considered. Because the main goal of operational products is to deliver accurate weather forecast the analyzing/forecasting model evolves continuously as improvements are made [e.g., Steiner et al., 2007]. Therefore results derived from this data set must be interpreted with caution and are given less weight in the present study.

\section{Comparison Between Lidar and AMSU-A}

\subsection{Annual Cycle}

[9] One important difference between AMSU-A brightness temperatures and lidar measured temperatures is that the former represent the averaged temperature in a layer defined by its weighting function, while the latter is representative of a mean temperature on an atmospheric layer of $3 \mathrm{~km}$. One possibility to bridge these differences could be the use the weighting functions for different AMSU channels to derive a temperature profile based on lidar measurements for comparison. However, because AMSU weighting functions varies, albeit weakly, with time (and space) this could lead to additional uncertainty in the comparison. Therefore we opted for a simpler, more direct approach, by comparing lidar to AMSU brightness temperature. The lidar corresponding levels to AMSU have been chosen based on the best agreement between the annual cycles derived by each data set, using only coincidental dates. Such results are shown in Table 2, which includes also a comparison between lidar and operational data. All temperature data shown in the present study are monthly averaged. A consistent comparison between lidar, AMSU and operational data such that the average absolute error between these three data is the smallest, leads to a choice of heightchannel-pressure level of [32 km-channel 12-7 hPa], [36 km-channel $13-5 \mathrm{hPa}$ ], [40 km-channel $14-3 \mathrm{hPa}$ ]. A comparison between the annual cycles for the strato-

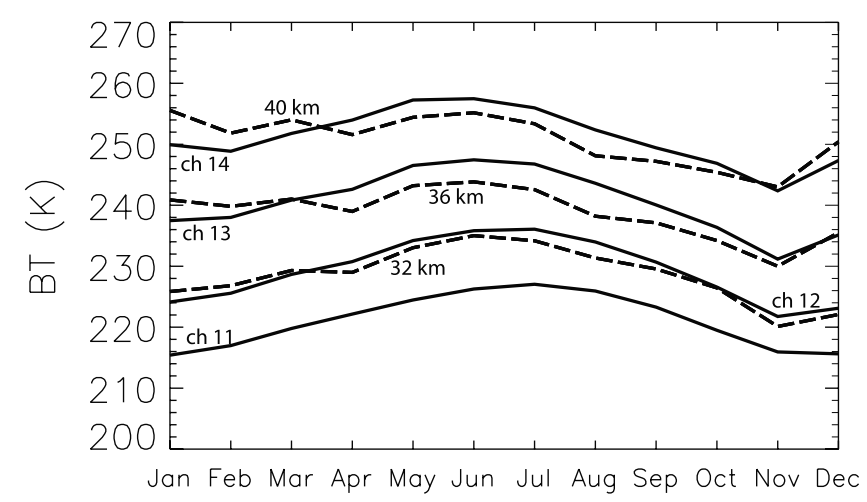

Figure 2. AMSU-A brightness temperature (K) annual cycle for different stratospheric channels (solid lines) and temperature (K) annual cycle for selected altitudes of OHP lidar measurements (dashed lines). 


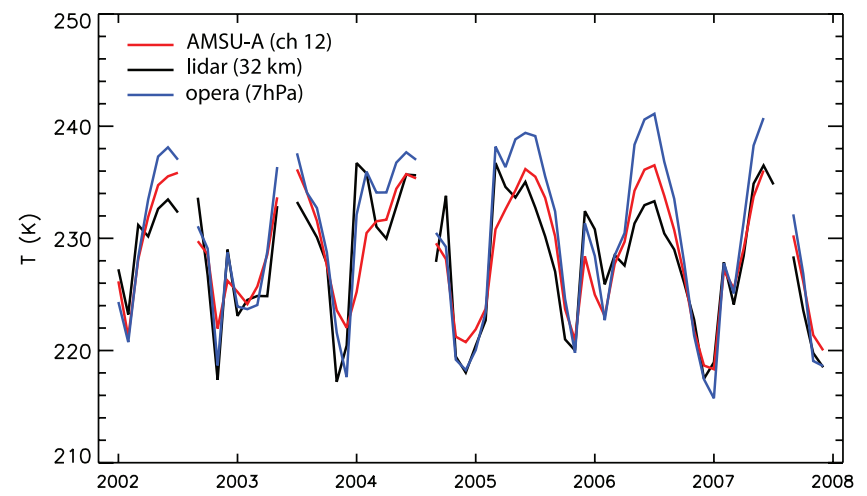

Figure 3. Temperature $(\mathrm{K})$ time series of lidar (black line) at $32 \mathrm{~km}$, AMSU-A channel 12 (red line), and operational data (blue line) at $7 \mathrm{hPa}$. spheric channels 11 through 14, and lidar measurements at 32,36 and $40 \mathrm{~km}$ (Figure 2) shows that there is good agreement between them, and supports our choice of levels/ channels. An additional comparison is presented in Figure 3 , which shows the temperature time series of lidar, AMSUA, and operational data for their common period (20022007) for the lowest level sets. Again, there is an overall good agreement between these data sets, with temperatures ranging between $\sim 210-240 \mathrm{~K}$ and the seasonal cycle well represented. Analysis of other levels and channels (not shown) confirm their relatively congruent behavior, despite their instrumental or instrument-model differences.

\subsection{Temporal and Spatial Sampling}

[10] In order to evaluate the effect of the temporal sampling on the agreement between the measurements, we calculated the linear correlation between monthly averaged lidar temperature anomalies (relative to the annual cycle), operational meteorological analyses and AMSU data, (a)

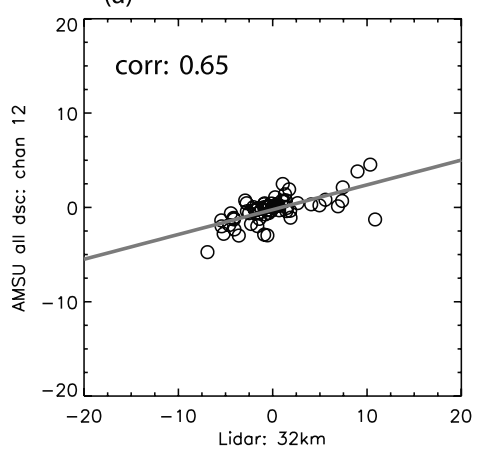

(d)

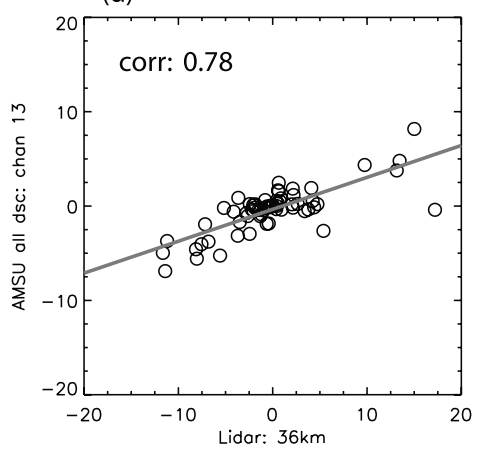

(g)

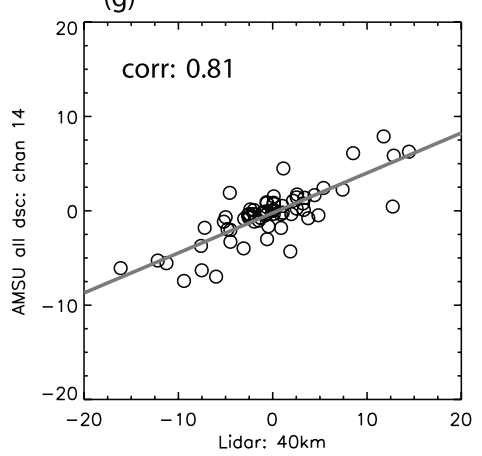

(b)

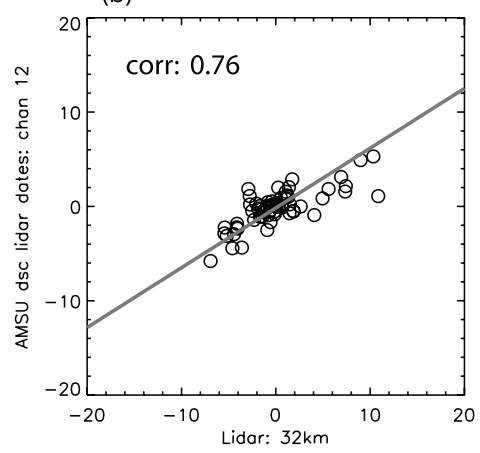

(e)

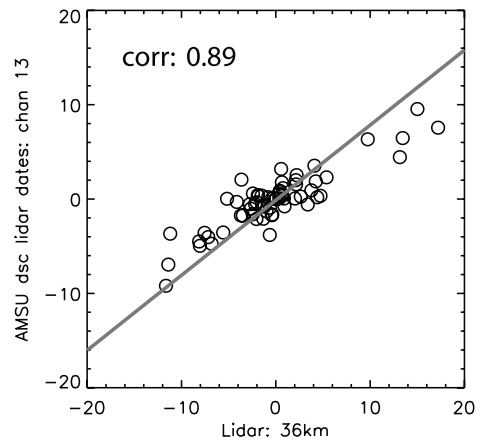

(h)

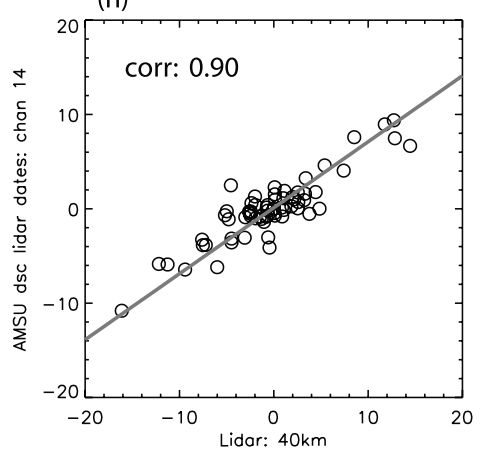

(c)
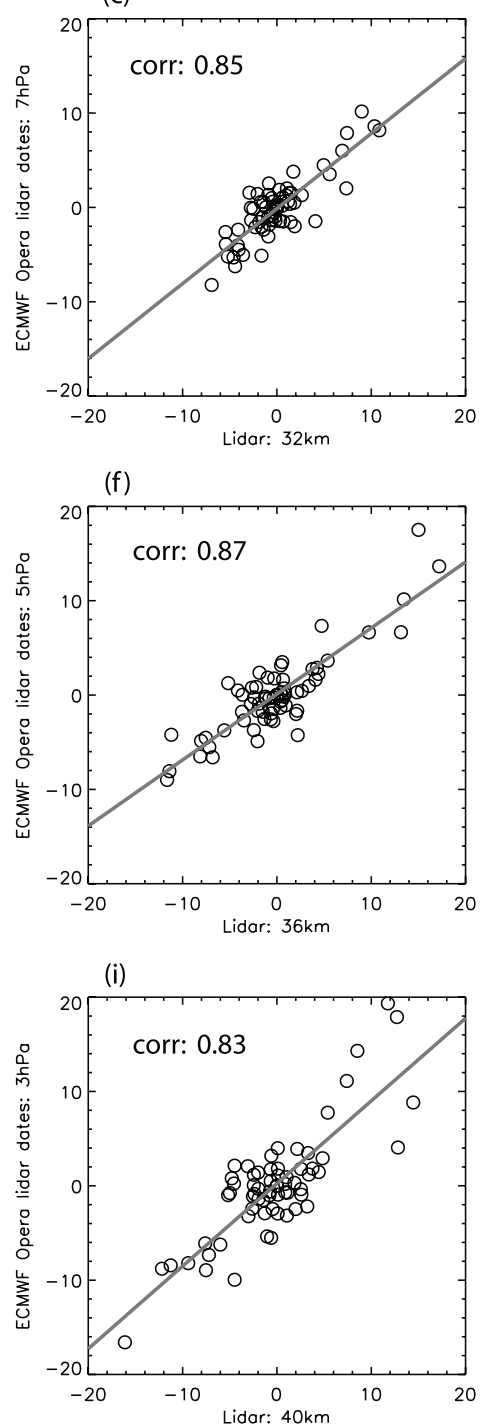

Figure 4. Least-squares fit between OHP lidar, AMSU-A and operational temperatures (in K, all with annual cycle removed), and respective linear correlations, for the period 2001-2007. Total number of measurements is 63 , and correlations are significant at $99 \%$. 
Table 3. Correlation Between Monthly Average Temperature Anomalies Derived From Lidar Measurements and AMSU or ECMWF Operational Data ${ }^{a}$

\begin{tabular}{cccc}
\hline Lidar & $\begin{array}{c}\text { AMSU } \\
\text { (All Dates) }\end{array}$ & $\begin{array}{c}\text { AMSU } \\
\text { (Lidar Dates) }\end{array}$ & $\begin{array}{c}\text { Operational } \\
\text { (Lidar Dates) }\end{array}$ \\
\hline $32 \mathrm{~km} / \mathrm{ch} 12 / 7 \mathrm{hPa}$ & $0.65(0.71)$ & $0.76(0.85)$ & $0.85(0.96)$ \\
$36 \mathrm{~km} / \mathrm{ch} 13 / 5 \mathrm{hPa}$ & $0.78(0.85)$ & $0.89(0.96)$ & $0.87(0.93)$ \\
$40 \mathrm{~km} / \mathrm{ch} 14 / 3 \mathrm{hPa}$ & $0.81(0.88)$ & $0.90(0.96)$ & $0.83(0.89)$ \\
\hline
\end{tabular}

${ }^{a}$ Values in brackets are correlations using winter measurements only (December through February). All values are significant at 99\% using the standard Student's $t$-test.

shown in Figure 4 and Table 3 (correlations significant at 99\% using Student's $t$-test). The correlation between lidar and AMSU data is larger when only the same dates of lidar measurements are considered in the calculation of the annual cycle and monthly anomalies (compare left and central columns of Figure 4). These correlations are as good as or better than the correlation between lidar and operational data set using same lidar dates (right column of Figure 4). When considering only the months of December through February the correlations are even higher, as shown in Table 3. The high correlation between AMSU and lidar data indicate that lidar measurements, taken locally, are still representative of a larger domain. However, the lower correlation when using different dates indicates that the temporal sampling has a non-negligible effect in the calculation of monthly mean anomalies.

[11] To further evaluate these differences, we have compared the annual cycle for AMSU-A channels 12 to 14 using all available night passes, and the annual cycles using "incomplete" (with or without lidar measurements) months. Figure 5 displays the results for channel 12 (which agrees well with lidar data at $32 \mathrm{~km}$, see Table 2). Because lidar measurements are done during night-time with clear sky, this analysis provides an indirect estimation of the effect of tropospheric cloud coverage on the calculation of monthly means and anomalies. In general, from mid-October to midMarch differences can reach several tenths of degree and there is large variability. Between March and October, the absolute difference is smaller, around $0.3 \mathrm{~K}$ which is the order of or smaller than the instrument noise (Table 1). This behavior is also observed for channels 13 and 14 (not shown). The reason for these differences between summer and winter are probably related to the effect of distinct seasonal radiative balances and to the larger dynamical variability during winter. This result suggests that the impact of temporal sampling is reduced in summer and seemingly more important in winter.

\subsection{Temperature Tendencies}

[12] Here an attempt is made to assess the effect of temporal sampling on the calculation of monthly means by evaluating the differences arising on the estimation of temperature tendencies. The term "tendency" is used instead of "trend" since the short data time span prevents strict trend calculations as a proxy of anthropogenic related response. A comparison between AMSU-A temperature tendencies calculated using monthly means based on same dates of lidar measurements and using all available night passes is shown in Table $4(\mathrm{a}, \mathrm{b})$. Temperature tendencies for both AMSU-A and lidar, using common dates, are strikingly similar (despite the somewhat higher uncertainty for lidar). However, AMSU-A derived temperature tendencies estimated using "complete" months are about $40 \%$ less negative than those calculated using only lidar dates. In all cases, the absolute tendency value is much higher than the estimated cooling of -0.4 to $-0.5 \mathrm{~K} /$ decade obtained from the SSU data record for the much longer period of 19792005 [Randel et al., 2008] for the mid to upper-stratosphere, between $30-50 \mathrm{~km}$. The negative tendencies found on both AMSU and lidar data sets are probably too large, and even considering a regular solar response as suggested by Keckhut et al. [2005] it will not explain such values. The effect of the descending phase of the 11-year solar cycle for the midlatitudes is of about -2 to $-3 \mathrm{~K}$ (zonal average, between $30-40 \mathrm{~km}$ ), but varies strongly with season [see, e.g., Figures 2 and 3 in the study of Keckhut et al., 2005]. Another source of discrepancy between the tendencies calculated here and SSU-derived trends is the spatial domain considered. SSU data is zonally averaged, while here we consider a restricted area for the tendency calculation. We re-calculated the temperature tendencies for AMSU night-time passes falling within the latitude band of 40 $45^{\circ} \mathrm{N}$ (without longitude restriction), and results are shown in Table 4 (c). There is a noticeable decrease in the tendency estimate compared to "locally" calculated tendencies especially for channels 13 and 14 (notice also that the temporal sampling effect is still evident). This analysis suggests that trends calculated based on zonal averages may smooth features that may be important in terms of local climate response. Longer time series of both lidar and AMSU are necessary to fully evaluate the impact of the temporal sampling on trend calculations, and for a more reliable estimate of the trend itself.

[13] While lidar data have the spatial and temporal sampling constraints, AMSU data may suffer from tidal effects due to orbital drift. Therefore we examined the differences between lidar and operational data, and lidar and AMSU to evaluate residual tendencies between these data sets which can give indication of the tidal effects.

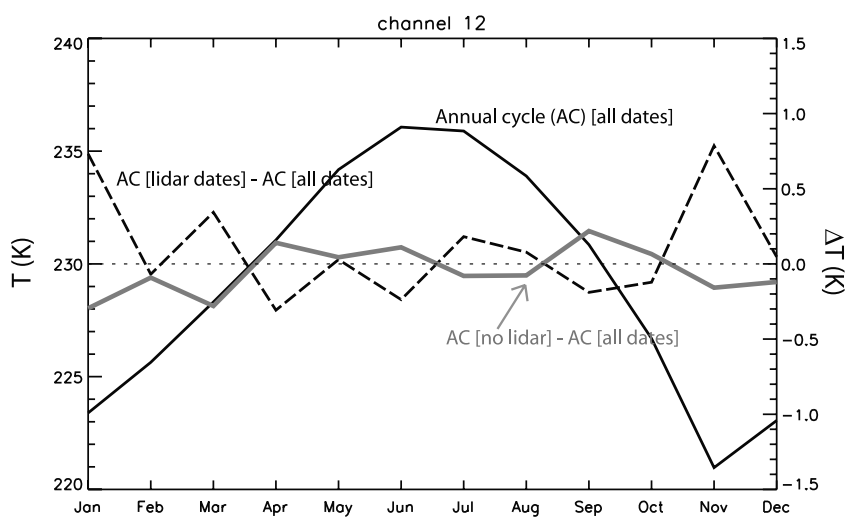

Figure 5. NOAA-16 AMSU-A channel 12 annual cycle brightness temperature (in $\mathrm{K}$, solid black line), using all dates, and differences between annual cycle temperatures using only days with OHP lidar measurements (in K, dashed line), or only dates without lidar measurements (in K, solid gray line). Channel 12 corresponds closely to an altitude of $32 \mathrm{~km}$, or $7 \mathrm{hPa}$ (see Table 2 and text for details). 
Table 4. Tendencies of Temperature With Respect to Time (in K/Decade) Based on Simple Linear Regression for the Period 2001-2007, for (a) OHP Lidar, (b) AMSU Nighttime Measurements Over Western Europe (40$45^{\circ} \mathrm{N}, 20^{\circ} \mathrm{W}-10^{\circ} \mathrm{E}$ ), and (c) AMSU Nighttime Measurements Falling Within the Latitudinal Band of $40-45^{\circ} \mathrm{N}$

\begin{tabular}{|c|c|c|c|c|c|c|}
\hline & \multirow[b]{2}{*}{ (a) Lidar OHP } & & \multicolumn{2}{|c|}{ (b) Western Europe } & \multicolumn{2}{|c|}{ (c) Zonal Average } \\
\hline & & & $\begin{array}{c}\text { AMSU } \\
\text { Lidar Dates }\end{array}$ & $\begin{array}{c}\text { AMSU } \\
\text { All Nights }\end{array}$ & $\begin{array}{c}\text { AMSU } \\
\text { Lidar Dates }\end{array}$ & $\begin{array}{c}\text { AMSU } \\
\text { All Nights }\end{array}$ \\
\hline $\begin{array}{l}32 \mathrm{~km} \\
36 \mathrm{~km} \\
40 \mathrm{~km}\end{array}$ & $\begin{array}{l}-2.5 \pm 2.6 \\
-4.4 \pm 3.2 \\
-5.0 \pm 3.2\end{array}$ & $\begin{array}{l}\text { ch } 12 \\
\text { ch } 13 \\
\text { ch } 14\end{array}$ & $\begin{array}{l}-2.8 \pm 1.1 \\
-4.6 \pm 1.8 \\
-4.8 \pm 2.0\end{array}$ & $\begin{array}{l}-1.6 \pm 0.7 \\
-2.5 \pm 1.2 \\
-2.5 \pm 1.4\end{array}$ & $\begin{array}{l}-2.0 \pm 0.8 \\
-2.6 \pm 1.1 \\
-2.1 \pm 1.2\end{array}$ & $\begin{array}{l}-1.4 \pm 0.5 \\
-1.8 \pm 0.8 \\
-1.5 \pm 1.0\end{array}$ \\
\hline
\end{tabular}

Figure 6 shows time series for lidar at $36 \mathrm{~km}$ minus operational data at $5 \mathrm{hPa}$, and lidar at $36 \mathrm{~km}$ minus AMSU channel 13. The residual tendency of lidar minus operational data is of $-5.2 \pm 3.2 \mathrm{~K} /$ decade (Figure $6 \mathrm{a}$ ), and indicates that tendencies derived from operational data are very feeble. This result confirms that, despite the high correlation between lidar and operational data (shown in the previous section), the use of the latter for trend calculations is not adequate due to successive improvements. On the other hand the residual temperature tendency of lidar minus AMSU are similar, however the uncertainty is larger than the residual trend itself $(-1.5 \pm 3.1 \mathrm{~K} /$ decade; Figure $7 \mathrm{~b})$. The origin of this residual tendency is likely related to tidal effects and the orbital drift of NOAA-16, as further dis-
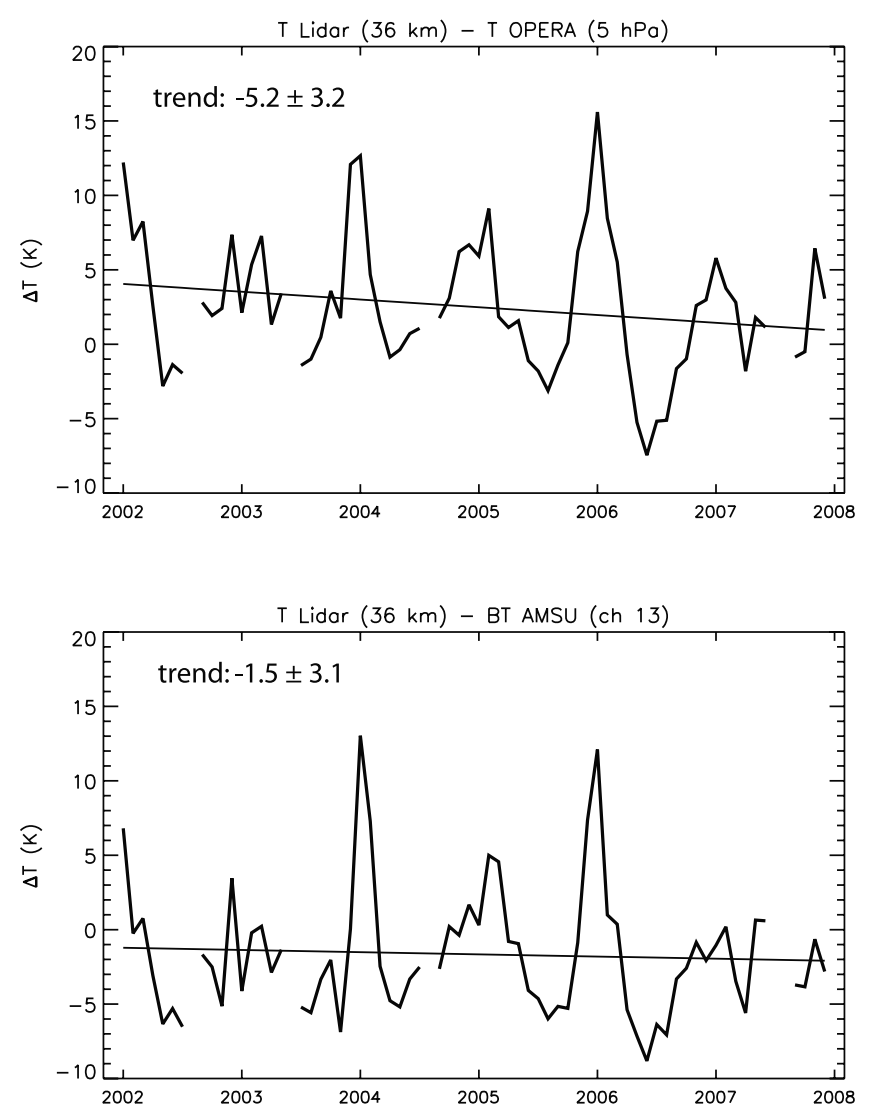

Figure 6. Residual tendencies of time series of (a) OHP lidar measurements at $36 \mathrm{~km}$ and ECMWF operational data at $5 \mathrm{hPa}$ and (b) OHP lidar measurements at $36 \mathrm{~km}$ and AMSU-A channel 13 data. Trends and uncertainties are in $\mathrm{K} /$ decade. (a) Channel 12 ASC-DSC (temperatures)

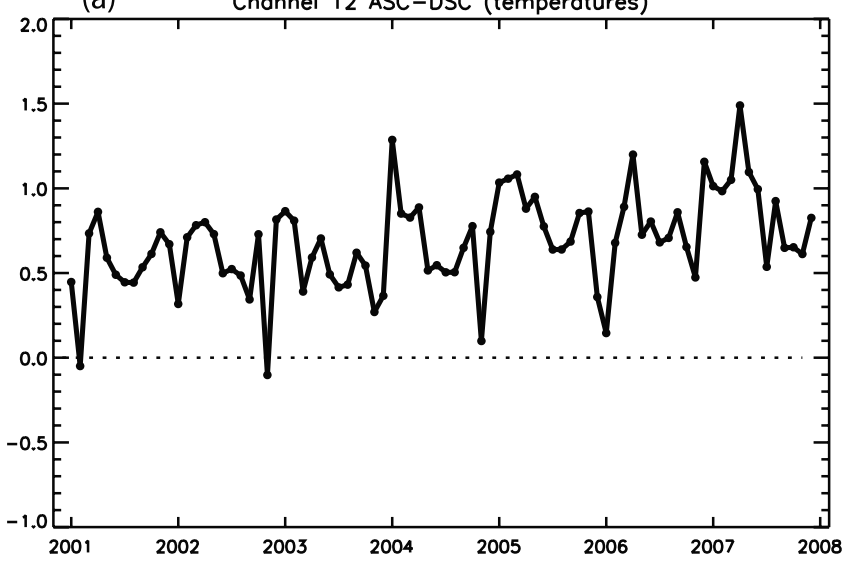

(b) Channel 13 ASC-DSC (temperatures)

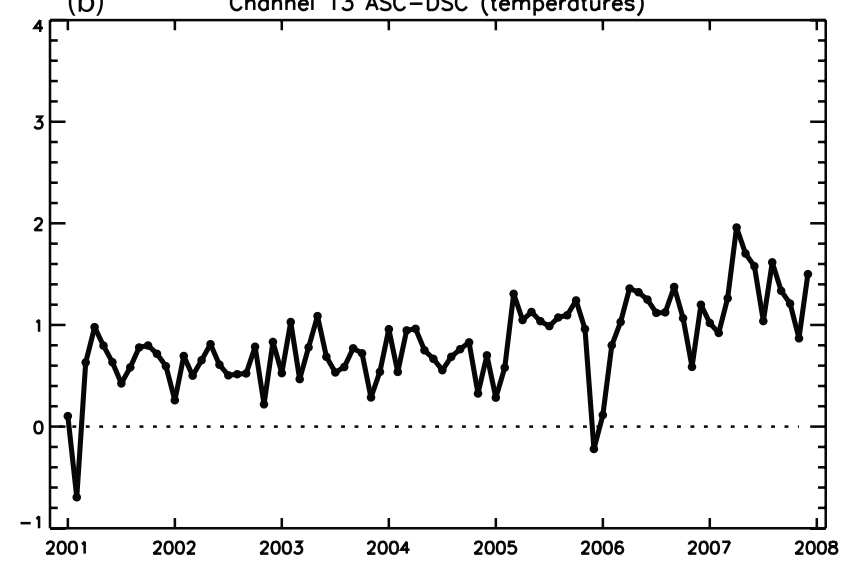

(c) Channel 14 ASC-DSC (temperatures)

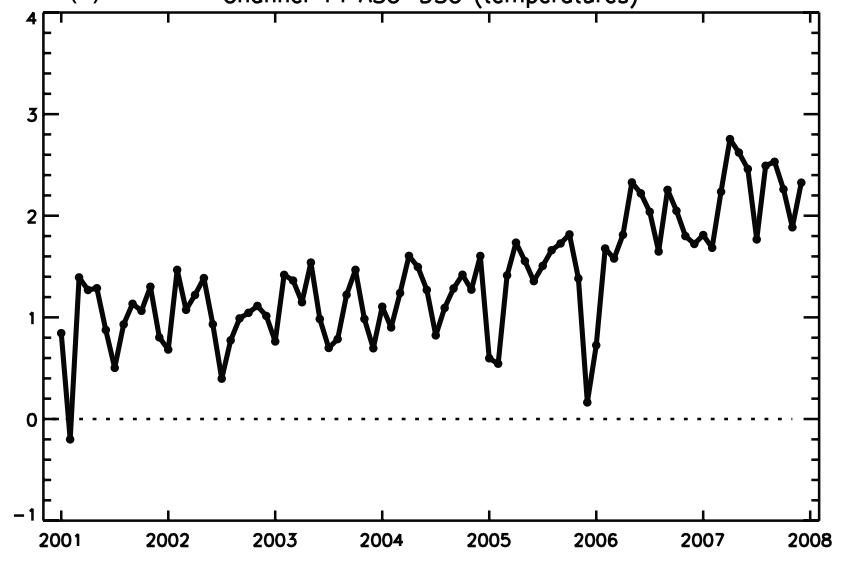

Figure 7. Monthly mean brightness temperature differences between NOAA-16 ascending and descending passes. 


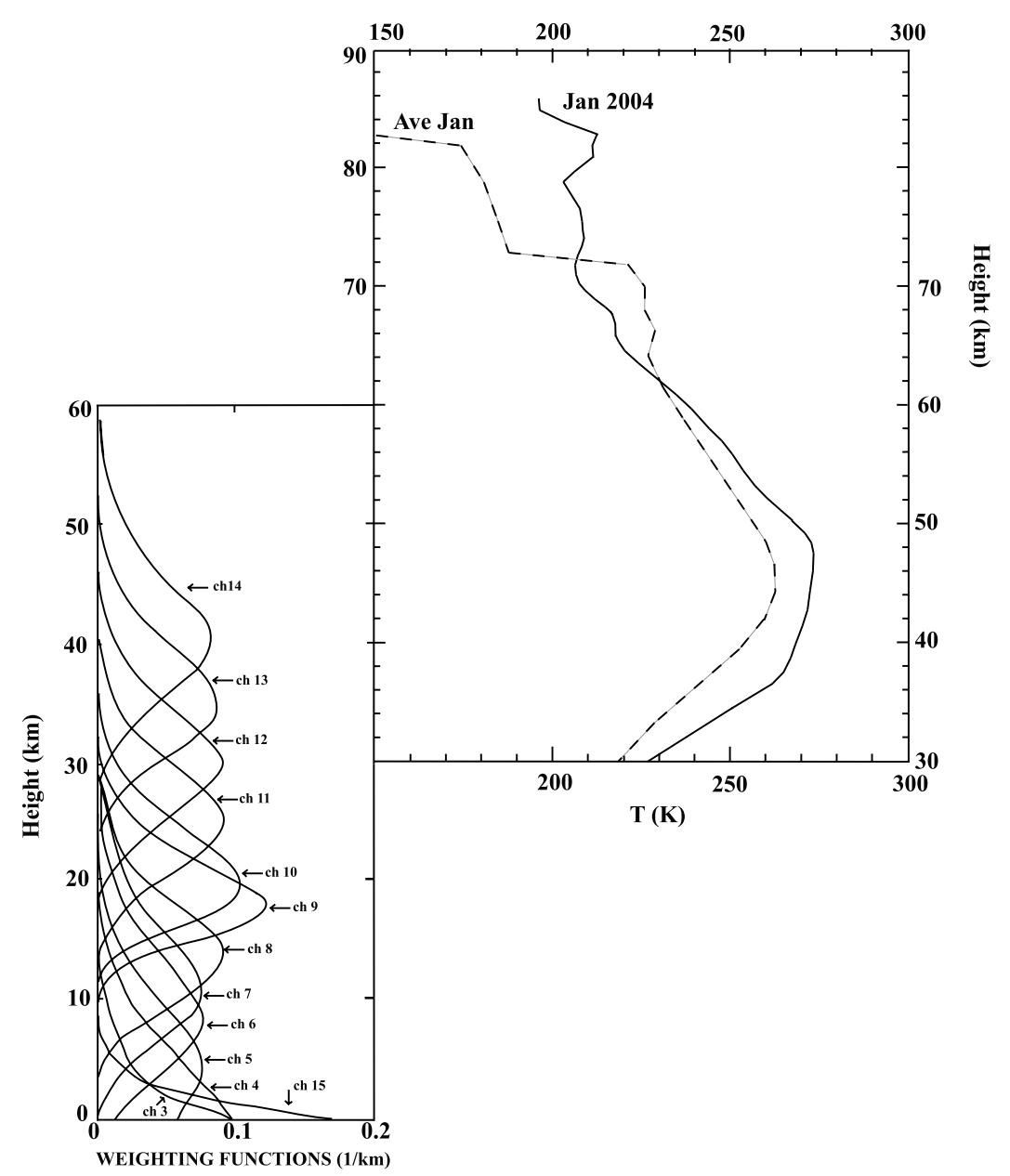

Figure 8. (Left) Weighting functions for a U.S. standard tropical atmosphere [from Karbou et al., 2005], and (right) vertical profile of temperature (K) from lidar measurements, for January 2004 (solid line) and average of all months of January between 2001 and 2007 except 2004 (dashed line).

cussed in section 4 , despite these long-term residual trend not being significant.

\section{Tidal Effects}

[14] Potential induced tidal effects have been investigated on the continuity of the OHP lidar series [Keckhut et al., 1999], however as measurements are mainly obtained in the first half of the night their impact on trends are minor. Early trends have been estimated [Keckhut et al., 1995] and revealed significant cooling of the lower mesosphere. Since this work, trend estimate have been updated showing a cooling of $1 \mathrm{~K} /$ decade in the upper stratosphere [Ramaswamy et al., 2001] increasing with altitude to a significant trend of $3 \mathrm{~K} /$ decade at $65 \mathrm{~km}$ [Beig et al., 2002]. OHP lidar temperature series have been used recently for ENVISAT validation [Ridolfi et al., 2007] and previously for the UARS validation [Fishbein et al., 1996; Hervig et al., 1996; Gille et al., 1996; Remsberg et al., 2002; Wu et al., 2003] and show that tides need to be taken into account [Keckhut et al., 1996]. Stratospheric temperatures provided by the successive SSU have shown discontinuities due to tides [Keckhut et al., 2001]; an alternate investigation, based on the radiance adjustments [Nash and Forrester, 1986] provides less tidal discontinuities [Randel et al., 2008]. According to bulletins reporting the orbital drift of NOAA-16, there has been an unsteady drift and consequent change in the equatorial crossing hour, from 14:24 UTC (northbound pass) in September 2000, to 14:30 UTC in December 2004, 14:52 UTC in September 2005 and 15:55 UTC in May 2007. The effect of the drift can be evaluated for example, by comparing the temperature differences between ascending and descending passes (Figure 7). While from 2001 until the end of 2004 there were not strong tendencies in the differences, there has been a noticeable increase in these differences from 2004, for channels 12 to 14. These differences increased from less than $1.5 \mathrm{~K}$ until 2004 to $2-3 \mathrm{~K}$ by the end of 2007, and are consistent with or somewhat larger than the tidal effect estimated by Keckhut et al. [1996], respectively of 0.6, 1.5, and $1.7 \mathrm{~K}$.

\section{Conclusions and Final Remarks}

[15] We present an assessment of the quality of two independent data sets for measurement and characterization of stratospheric temperature, namely, the Rayleigh Lidar at the Observatoire de Haute-Provence, and NOAA-16 AMSU upper-stratospheric channels (12-14). The lidar data has the 
advantage of long-term continuity for trend estimates, while AMSU is the sole current source of global stratospheric temperature data, and expected to be in service for at least the next decade. An important difference in the nature of lidar and AMSU measurements is that while lidar data is vertically averaged over a thin layer of $3 \mathrm{~km}$ only, AMSU data represents the integrated contribution of a deep atmospheric layer and takes into account contributions of layers in the middle and upper stratosphere with distinct behavior, smoothing an otherwise sharp peak in temperature. This may explain sharp, pointwise differences, as seen for example in January 2004 and 2006 (Figure 6b) when lidar and AMSU temperatures differed by more than $10 \mathrm{~K}$. To illustrate this point, we present Figure 8, which shows the average temperature profile for all months of January except 2004, and the average profile for January 2004. Between 30 and $63 \mathrm{~km}$, the average temperature was around $10 \mathrm{~K}$ higher than the average profile, decreasing toward $63 \mathrm{~km}$. At the same time, the weighting function of channel 13, for example, peaks at around $35 \mathrm{~km}$ but includes contributions from 20 to $60 \mathrm{~km}$. Therefore, while at around $35 \mathrm{~km}$ the temperature is $10 \mathrm{~K}$ higher than average, AMSU consider the layer between 20 and $60 \mathrm{~km}$, which will yield a colder value than the lidar measurements.

[16] Despite these vertical sampling differences, our analysis shows that there is good agreement between AMSU and OHP lidar monthly averaged temperatures, seasonal cycle and tendencies, when considering same measurement dates. This indicates that although lidar measurements are spatially restricted, they are representative of a relatively larger domain in a monthly mean timescale. The effect of the temporal sampling was more pronounced, with weaker correlation between AMSU and lidar data when monthly means were calculated for different days. For example, the linear correlation between AMSU and OHP lidar increased by 11 to $17 \%$ when considering only coincidental dates and the improvement is larger for the lower altitudes. Also, the lidar and AMSU-based temperature tendencies for the period 2001 to 2007 had very good agreement for the three levels/channels when using only coincidental dates, but AMSU-based tendency was about $40 \%$ less negative when all available dates were used. When considering zonally averaged mid-latitude time series for the same period, the tendencies are weaker (i.e., less cooling) however the temporal effect is still present, although the differences are reduced to around $30 \%$. Finally, AMSU measurements must be corrected for tidal effects due to satellite drift, particularly in higher levels (near the stratopause) where tidal effects are more important [Keckhut et al., 1996]. While good agreement between both data sets has been reported here, sampling and tides are major issues for trend estimates. A somewhat longer series of AMSU temperatures will be required to estimate present temperature trends but this is expected through space agency agreement for selecting sentinel missions including AMSU. Also time of the day adjustments related to tides should be applied; in this respect the effort performed under the tidal CAWSES (Climate and Weather of the Sun-Earth System) campaign (http://www.bu.edu/cawses/globalcampaign.html) will be very useful. While some efforts to provide ground-based temperature are performed within the NDACC, the number of series remains too small.
[17] Acknowledgments. This work is a contribution to the project GEOmon (Global Earth Observation and Monitoring of the atmosphere). AMSU data were obtained through the French Mixed Service Unit ICARE. The authors appreciate the comments and suggestions of three anonymous reviewers, which led to the improvement of the article.

\section{References}

Beig, G., et al. (2002), Review of mesospheric temperature trends, Rev. Geophys., 41(4), 1015, doi:10.1029/2002RG000121.

Cagnazzo, C., C. Claud, and S. Hare (2006), Aspects of stratospheric longterm changes induced by ozone depletion, Clim. Dyn., doi:10.1007/ s00382-006-0120-1.

Eyring, V., et al. (2007), Multimodel projections of stratospheric ozone in the 21 st century, J. Geophys. Res., 112, D16303, doi:10.1029/ 2006JD008332.

Fishbein, R. E., et al. (1996), Validation of UARS MLS temperature and pressure measurements, J. Geophys. Res., 101, 9983-10,016, special issue on UARS Data Validation.

Forster, P. M. de F., and K. P. Shine (1997), Radiative forcing and temperature trends from stratospheric ozone changes, J. Geophys. Res., 102, $10,841-10,855$.

Free, M., and D. J. Seidel (2005), Causes of differing temperature trends in radiosonde upper air datasets, J. Geophys. Res., 110, D07101, doi:10.1029/2004JD005481.

Gille, J. C., et al. (1996), Accuracy and precision of cryogenic limb array etalon spectrometer (CLAES) temperature retrievals, J. Geophys. Res., $101,9583-9602$, special issue on UARS Data Validation.

Goldberg, M. D., D. S. Crosby, and L. Zhou (2001), The limb adjustment of AMSU-A observations: Methodology and validation, J. Appl. Meteorol., $40,70-83$

Hare, S. H. E., L. J. Gray, W. A. Lahoz, A. O Neill, and L. Steenman-Clark (2004), Can stratospheric temperature trends be attributed to ozone depletion?, J. Geophys. Res., 109, D05111, doi:10.1029/2003JD003897.

Hauchecorne, A., and M. L. Chanin (1980), Density and temperature profiles obtained by lidar between $35-\mathrm{km}$ and $70-\mathrm{km}$, Geophys. Res. Lett., 7, $565-568$.

Hervig, M. E., et al. (1996), A validation of temperature measurements from the halogen occultation experiment, J. Geophys. Res., 101, 10,27710,286, special issue on UARS Data Validation.

Intergovernmental Panel on Climate Change (IPCC) (2001), Climate change 2001: The scientific basis, in Contribution of Working Group I to the Third Assessment Report of the Intergovernmental Panel on Climate Change, edited by J. T. Houghton et al., 881 pp., Cambridge Univ. Press, New York.

Karbou, F., F. Aires, C. Prigent, and L. Eymard (2005), Potential of Advanced Microwave Sounding Unit-A (AMSU-A) and AMSU-B measurements for atmospheric temperature and humidity profiling over land, J. Geophys. Res., 110, D07109, doi:10.1029/2004JD005318.

Keckhut, P., A. Hauchecorne, and M. L. Chanin (1993), A critical review of the database acquired for the long-term surveillance of the middle atmosphere by the French Rayleigh lidars, J. Atmos. Oceanic Technol., 10, $850-867$.

Keckhut, P., A. Hauchecorne, and M. L. Chanin (1995), Mid-latitude longterm variability of the middle atmosphere trends, and cyclic and episodic changes, J. Geophys. Res., 100, 18,887-18,897.

Keckhut, P., et al. (1996), Semi-diurnal and diurnal temperature tides $(30-55 \mathrm{~km})$ : Climatology and effect on UARS-lidar data comparisons, J. Geophys. Res., 101, 10,299-10,310, special issue on UARS Data Validation.

Keckhut, P., F. J. Schmidlin, A. Hauchecorne, and M. L. Chanin (1999), Stratospheric and mesospheric cooling trend estimates from US rocketsondes at low latitude stations ( 8 degrees $\mathrm{S}-34$ degrees $\mathrm{N})$, taking into account instrumental changes and natural variability, J. Atmos. Sol. Terr. Phys., 61, 447-459.

Keckhut, P., J. Wild, M. Gelman, A. J. Miller, and A. Hauchecorne (2001), Investigations on long-term temperature changes in the upper stratosphere using lidar data and NCEP analyses, J. Geophys. Res., 106, $7937-7944$.

Keckhut, P., et al. (2004), Review of ozone and temperature lidar validations performed within the framework of the network for the detection of stratospheric change, J. Environ. Monit., 6, 721-733.

Keckhut, P., C. Cagnazzo, M.-L. Chanin, C. Claud, and A. Hauchecorne (2005), The 11-year solar-cycle effects on the temperature in the upperstratosphere and mesosphere, part I: Assessment of observations, J. Atmos. Sol. Terr. Phys., 67, 940-947.

Kurylo, M. J., and S. Solomon (1990), Network for the detection of stratospheric change: A status and implementation report, in NASA Upper Atmosphere Research Program and NOAA Climate and Global Change Program (NASA), NASA Technical Report, Washington, D. C. 
Lahoz, W. A. (2000), Northern hemisphere winter stratospheric variability in the Met Office Unified Model, Q. J. R. Meteorol. Soc., 126, 26052630.

Langematz, U., M. Kunze, K. Kruger, K. Labitzke, and G. L. Roff (2003), Thermal and dynamical changes of the stratosphere since 1979 and their link to ozone and $\mathrm{CO}_{2}$ changes, J. Geophys. Res., 108(D1), 4027 , doi:10.1029/2002JD002069.

Manzini, E., B. Steil, C. Bruehl, M. A. Giorgetta, and K. Krueger (2003), A new interactive chemistry-climate model, 2: Sensitivity of the middle atmosphere to ozone depletion and increase in greenhouse gases and implications for recent stratospheric cooling, J. Geophys. Res., 108(D14), 4429, doi:10.1029/2002JD002977.

Nash, J., and G. F. Forrester (1986), Long-term monitoring of stratospheric temperature trends using radiance measurements obtained by the TIROSN series of NOAA spacecraft, Adv. Space Res., 6(10), 37-44.

Overland, J., J. Turner, J. Francis, N. Gillett, G. Marshall, and M. Tjernström (2008), The Arctic and Antarctic: Two faces of climate change, Eos Trans. $A G U, 89(19), 177$, doi:10.1029/2008EO190001.

Ramaswamy, V., et al. (2001), Stratospheric temperature trends: Observations and model simulations, Rev. Geophys., 39, 71-122.

Randel, W., et al. (2008), An update of observed stratospheric temperature trends, J. Geophys. Res., doi:10.1029/2008JD010421, in press.

Remsberg, E. E., et al. (2002), An assessment of the quality of Halogen Occultation Experiment temperature profiles in the mesosphere with Rayleigh backscatter lidar and inflatable falling sphere measurements, J. Geophys. Res., 107(D19), 4447, doi:10.1029/2001JD001521.

Ridolfi, M., et al. (2007), Geophysical validation of temperature retrieved by the ESA processor from MIPAS/ENVISAT atmospheric limb-emission measurements, Atmos. Chem. Phys., 7, 4459-4487.

Shine, K. P. (2003), A comparison of model simulated trend in stratospheric temperature, Q. J. R. Meteorol. Soc., 129, 1569-1588.

Shine, K. P., J. J. Barnett, and W. J. Randel (2008), Temperature trends derived from stratospheric sounding unit radiances: The effect of increasing $\mathrm{CO}_{2}$ on the weighting function, Geophys. Res. Lett., 35, L02710, doi:10.1029/2007GL032019.
Singh, U. N., P. Keckhut, T. J. McGee, M. R. Gross, A. Hauchecorne, E. F. Fishbein, J. W. Waters, J. C. Gille, A. E. Roche, and J. M. Russell III (1996), Stratospheric temperature measurements by two collocated NDSC lidars at OHP during UARS validation campaign, J. Geophys. Res., 101, 10,287-10,298, special issue on UARS Data Validation.

Scaife, A., J. Knight, G. Vallis, and C. Folland (2005), A stratospheric influence on the winter NAO and North Atlantic surface climate, Geophys. Res. Lett., 32, L18715, doi:10.1029/2005GL023226.

Sigmond, M., J. F. Scinocca, and P. J. Kushner (2008), Impact of the stratosphere on tropospheric climate change, Geophys. Res. Lett., 35, L12706, doi:10.1029/2008GL033573.

Simmons, A., M. Hortal, G. Kelly, A. McNally, A. Untch, and S. Uppala (2005), ECMWF analysis and forecasts of stratospheric winter polar vortex breakup: September 2002 in the Southern Hemisphere and related events, J. Atmos. Sci., 62, 668-689.

Song, Y., and W. A. Robinson (2004), Dynamical mechanisms for stratospheric influences on the troposphere, J. Atmos. Sci., 61, 1711-1725.

Steiner, A. K., G. Kirchengast, M. Borsche, U. Foelsche, and T. Schoengassner (2007), A multi-year comparison of lower stratospheric temperatures from CHAMP radio occultation data with MSU/AMSU records, J. Geophys. Res., 112, D22110, doi:10.1029/2006JD008283.

Wu, D. L., et al. (2003), Mesospheric temperature from UARS MSL: Retrieval and validation, J. Atmos. Sol. Terr. Phys., 65, 245-267.

C. Claud and B. M. Funatsu, Laboratoire de Météorologie Dynamique/ IPSL, CNRS, Ecole Polytechnique, 91128 Palaiseau, France. (chantal. claud@1md.polytechnique.fr; funatsu@lmd.polytechnique.fr)

A. Hauchecorne and P. Keckhut, Service d'Aéronomie/IPSL, Université Versailles St-Quentin, CNRS, Route des Gatines, 91371 Verrières-le Buisson, Cedex, France. (alain.hauchecorne@aerov.jussieu.fr; philippe. keckhut@aerov.jussieu.fr) 